\title{
Immunohistochemical Localization of Laminin in the Periodontal Ruffini Endings of Rat Incisors: A Possible Function of Terminal Schwann Cells*
}

\author{
Takeyasu Maeda ${ }^{1}$, Osamu Sato ${ }^{1}$, Koichi Kannari ${ }^{1}$, Hiroo TaKagi ${ }^{2}$ and Toshihiko Iwanaga ${ }^{3}$ \\ Department of Oral Anatomy ${ }^{1}$, Niigata University School of Dentistry, Niigata; Department of Oral Surgery ${ }^{2}$, Nihon University \\ School of Dentistry at Matsudo, Matsudo; Department of Anatomy ${ }^{3}$, Niigata University School of Medicine, Niigata, Japan
}

Received March 22, 1991

\begin{abstract}
Summary. Ruffini endings in the periodontal ligament of rodents are ensheathed by a special type of terminal Schwann cell with a particularly developed rough endoplasmic reticulum and Golgi apparatus, and further enveloped by a characteristic multi-layered structure. In order to reveal the functional significance of the structures, localization of a laminin molecule in the periodontal Ruffini endings of rats was immunohistochemically investigated at the levels of light and electron microscopy.

Immunostaining using an anti-laminin serum clearly demonstrated the profiles of the Ruffini endings as well as those of the blood vessels. Ultrastructurally, reaction products for laminin were deposited in the entire thickness of the multi-layered structure, supporting the idea that this structure is derived from the basal lamina. The basal lamina, immunoreacting with laminin antiserum, was penetrated by periodontal collagen fibers, possibly serving as an adhesive device between the Ruffini endings and surrounding collagen fibers. The laminin immunoreactive materials were also recognized in the vesicles and caveolae of the terminal Schwann cells which tended to gather at the interstitial surface of the cells. The terminal Schwann cells are therefore believed to be directly involved in the formation of the multilayered basal lamina through the active production of its materials.
\end{abstract}

The basal lamina is an extracellular matrix that connects various types of cells with connective tissue elements, especially with collagen fibers. Biochemical and immunohistochemical studies have revealed that the basal lamina is composed of type IV collagen and several glycoproteins including laminin and fibronectin (LAURIE et al., 1982; LEBLOND and INOUE, 1989). In the peripheral nervous tissue, the basal lamina is present exclusively at the surface of Schwann cells, its chemical composition being essentially identical to that in other tissues. Laminin and fibronectin have been reported to be involved in the attachment of Schwann cells to the basal lamina, and in that of basal lamina to connective tissue elements, respectively (IDE and TOHYAMA, 1984). On the other hand, immunohistochemical studies using cultured nervous tissue have shown that the immunoreactivity for laminin is restricted to the basal lamina ensheathing Schwann cells, while the fibronectin immunoreactivity is expressed in association with fibroblasts, but not Schwann cells (BROCKEs et al., 1979; EvERCOOREN et al., 1982; CORNBROOKS et al., 1983). Thus, laminin is a useful marker substance for identifying the basal lamina associated with Schwann cells.

Recent morphological studies have shown that the Ruffini nerve endings, responsible for the perception of tension in collagen fibers, act as essential mechanoreceptors distributed in the periodontal ligament of rodents (BYERS, 1985; MAEDA et al., 1987; SATO et al., 1988, 1989; KANNARI, 1990). The periodontal Ruffini endings are ultrastructurally characterized by expanded axon terminals which are invested by a multilayered structure, presumably derived from the basal lamina (BYERS, 1985; MAEDA et al., 1989; KANNARI, 1990). This is a unique formation frequently recognized in the periodontal Ruffini endings of rodents (BYers, 1985; MAeda et al., 1989; KAnNARI, 1990).

\footnotetext{
*This study was supported by a Grant-in-Aid for Scientific Research (No. 63440069) from the Ministry of Education, Science and Culture, Japan.
} 
However, little information has been available regarding its mechanism of formation and functional significance. Another notable finding is that the periodontal Ruffini endings are associated with terminal Schwann cells which contain a conspicuously welldeveloped endoplasmic reticulum and Golgi apparatus, features which are hardly encountered in ordinary Schwann cells. This peculiar characteristic of the terminal Schwann cells suggests that the cells may be involved in mechanoreception through the active synthesis of proteins of the lamellar structure, in addition to ordinary functions such as the support and nourishment of nerve terminals (MAEDA et al., 1989, 1990).

The present study was designed to clarify the origin and functional significance of the multi-layered structure in the periodontal Ruffini endings by means of immunohistochemistry for laminin at the levels of light and electron microscopy.

\section{MATERIALS AND METHODS}

\section{Experimental animals}

The lingual periodontal ligament of the upper incisors, obtained from adult male Wistar rats, was used for immunohistochemical examination. The rats were deeply anesthetized with an intraperitoneal injection of sodium pentobarbiturate, and fixed by transcardiac perfusion with a periodate-lysine-paraformaldehyde fixative (MCLEAN and NAKANE, 1974). The jaws were dissected out immediately, and postfixed in the same fixative for additional $6 \mathrm{~h}$. The tissues were decalcified with $4.13 \%$ EDTA-2Na for 2 weeks at $4{ }^{\circ} \mathrm{C}$ and then equilibrated in $30 \%$ sucrose solution overnight. Cryostat sections, $15-20 \mu \mathrm{m}$ in thickness, were prepared by use of a Coldtome (Sakura Co. Ltd., Tokyo, Japan).

\section{Immunohistochemistry for laminin}

Immunohistochemistry was carried out with freefloating sections after inactivating endogenous peroxidase with $0.3 \% \mathrm{H}_{2} \mathrm{O}_{2}$ in absolute methanol for 10 $\min$. The sections were processed for the peroxidase- antiperoxidase (PAP) method according to STERN BERGER (1979). The sections were incubated with a laminin antiserum (AB-1220, Advance Co. Ltd., Tokyo, Japan) diluted $1: 2,500$ for $72 \mathrm{~h}$ at $4^{\circ} \mathrm{C}$. After rinsing with $0.01 \mathrm{M}$ phosphate buffered saline (PBS, pH 7.3), the sections were incubated with porcine anti-rabbit IgG (1:60, Dakopatts, Glustrup, Denmark), followed by rabbit PAP complex (1:120, Dakopatts, Glustrup, Denmark). An enzyme reaction was developed with a mixture of diaminobenzidine tetrahydrochloride (DAB, $0.02 \%$ ) and $\mathrm{H}_{2} \mathrm{O}_{2}(0.01 \%)$ in $0.05 \mathrm{M}$ Tris buffer, $\mathrm{pH}$ 7.6.

For electron microscopy, cryostat sections were mounted on poly-L-lysine coated glass slides, and stained with the PAP method using the laminin antiserum. For sufficient penetration of the antibodies, some of the sections were treated with a PBS containing $0.02 \%$ saponin before immunostaining. The immunostained sections were postfixed in $1 \%$ $\mathrm{OsO}_{4}$, dehydrated through a graded series of ethanol and embedded in Epon 812. Ultrathin sections with or without electron staining by uranyl acetate were examined with an H-7000 transmission electron microscope (Hitachi Co. Ltd., Tokyo, Japan).

A non-immune serum replaced the primary antibody for immunocontrol sections. The control sections incubated in the non-immune serum did not show any specific DAB labeling.

\section{RESULTS}

\section{Light microscopic observations}

The immunohistochemistry for laminin was able to clearly demonstrate the neural and vascular basal laminae distributed in the lingual periodontal ligament of rat incisors. Both immunopositive neural and vascular elements were restricted to the alveolar half of the periodontal ligament designated as the alveolusrelated part by BEERTSEN et al. (1974), while no immunoreaction was present in the other half, or the tooth-related part, except around the epithelial cells of the Hertwig's root sheath (Fig. 1a). It was easy to distinguish the vascular basal lamina from the neural

Fig. 1. a. The lingual periodontal ligament $(P L)$ of the rat incisor. PAP staining by use of a laminin antiserum. Neural and vascular elements in the alveolar half of the periodontal ligament are intensely reactive to the laminin antiserum, while no immunoreaction is present in the tooth half except around the epithelial cells of Hertwig's root sheath (arrowheads). $A B$ alveolar bone, $B V$ blood vessels, $D$ dentin, $N B$ nerve bundle. $\times 170$. b. Higher magnification of the boxed area in Fig. 1a. The laminin immunopositive nerves ramify in a dendritic fashion to form Ruffini endings. Some rounded cells showing the laminin immunoreactivity (arrows) are observed in contact with Ruffini endings. PL periodontal ligament. $\times 550$ 


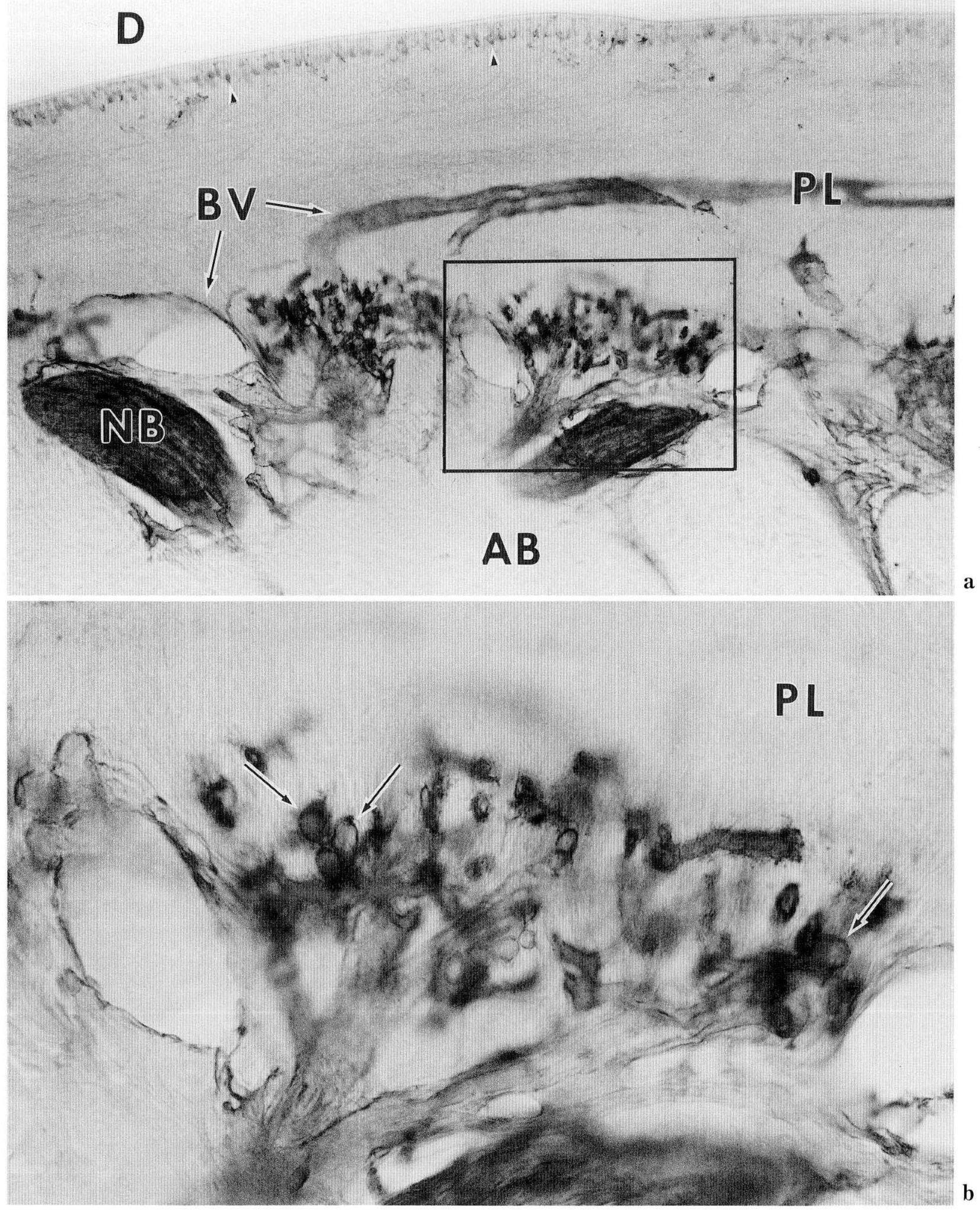

Fig. 1. Legend on the opposite page. 


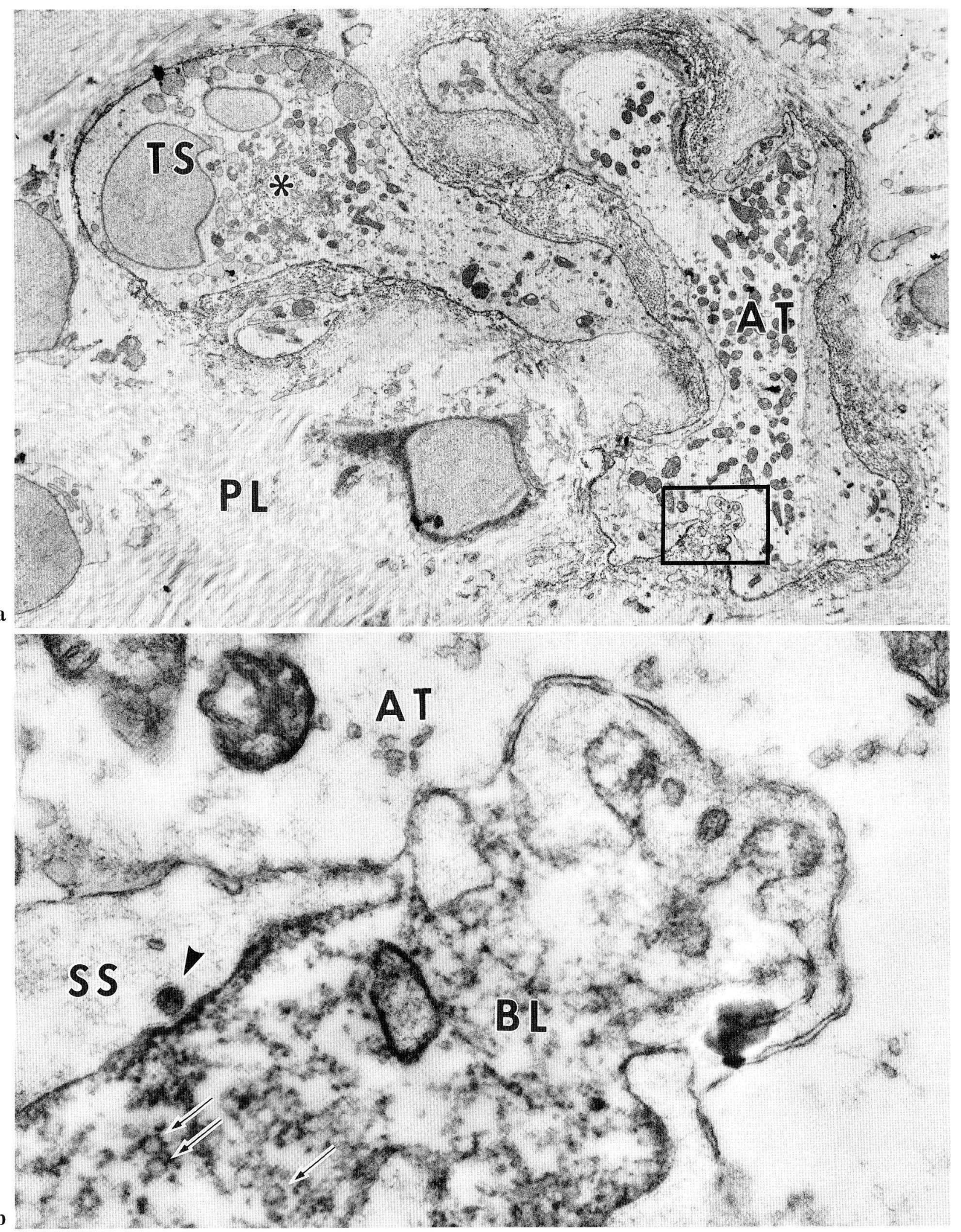

Fig. 2. Legend on the opposite page. 
one according to the arrangement and intensity of the immunoreaction. The immunoreactivity in the basal lamina of blood vessels displayed two parallel lines with a thin space between them, while that in the basal lamina of nerves, especially at the terminals, was represented by non-parallel lines with an expanded space, and was more intense than in the blood vessels.

The basal lamina surrounding the nerves, immunoreactive for laminin, was densely distributed in the mid-region of the lingual periodontal ligament, displaying a dendritic fashion (Fig. 1a). From their arborization and terminal formation, the immunopositive structures were identified as Ruffini nerve endings such as we previously demonstrated by immunohistochemistry for neurofilament protein and S-100 protein (SATO et al., 1988, 1989; MAEDA et al., 1989). The outlines of the laminin immunoreactivity in the Ruffini endings were thicker than those demonstrable around preterminal nerve bundles and blood vessels (Fig. 1b).

Rounded cells whose outlines were immunoreactive for laminin frequently occurred near the axon terminals of Ruffini endings (Fig. 1b). The linear immunoreactivity around the cell bodies was thinner than that associated with the Ruffini endings. The cells were rich in cytoplasm and contained an indented nucleus; their nucleus and cytoplasm were negative in immunoreaction. These morphological features and the topographic relationship with the Ruffini endings indicated that this cell type was a terminal Schwann cell associated with Ruffini endings, as previously reported (MAEDA et al., 1989, 1990).

\section{Electron microscopic observation}

The axon terminals of the Ruffini endings were identified as expanded portions which were filled with a large number of mitochondria, and covered by a thick Schwann sheath (Fig. 2a). The laminin immunoreactive materials, recognizable as electron dense materials, were lamellarly deposited in the multilayered structure distributed around the axon terminals of the Ruffini endings (Figs. 2, 3a), suggesting that each lamina densa was immunostained positively. The most intense immunoreaction was recognized in the innermost layer of the basal laminae. The collagen fibers, which were negative in reaction, were observed within the immunopositive masses; the immunopositive materials also appeared to be deposited around the collagen fibers in the vicinity of the axon terminals (Figs. 2, 4). The major population of periodontal collagen fibers did not directly contact the fingerlike projections extending from the axon terminals, the laminin positive materials interposing between the collagen fibers and the fingerlike projections. A single layer of the basal lamina showing laminin immunoreactivity was observed around the cell bodies of terminal Schwann cells.

Another positive immunoreaction for laminin was localized in the caveolae and vesicles dispersed in the cell bodies and cytoplasmic extensions of the terminal Schwann cells (Fig. 5). The periaxonal Schwann sheath contained numerous immunolabelled caveolae and cytoplasmic vesicles which tended to gather at the margin facing the multi-layered basal lamina (Fig. 3b). No immunoreactivity was found in cytoplasmic caveolae and vesicles facing the periaxonal space (Fig. 3b). Immunostaining with and without pretreatment with saponin did not demonstrate any reaction products in their cytoplasm or cell organellae, including the cisternae of the endoplasmic reticulum, Golgi apparatus, and nuclear membrane.

In spite of careful observations, we failed to recognize reaction products in the caveolae and vesicles of ordinary Schwann cells. Furthermore, none of the fibroblasts distributed widely in the periodontal ligament showed laminin immunoreactivity.

\section{DISCUSSION}

The present immunohistochemical study for laminin supported the notion that the multi-layered structure in the periodontal Ruffini endings is derived from the basal lamina. As the multi-layered basal lamina is not recognizable in the Ruffini endings of other tissues (cf. ANDRES and DÜRING, 1973), it is presumed to be

Fig. 2. a. Electron micrograph of Ruffini endings in the periodontal ligament $(P L)$ of the rat incisor. The materials were stained by the pre-embedding method for laminin. Multi-layered immunopositive materials surround mitochondria-rich axon terminals $(A T)$ and terminal Schwann cell (TS) containing well-developed cell organellae $(*)$. The most intense immunoreaction is observed in the innermost layer of the basal lamina. $\times 5,000$. b. Higher magnification of the box in Fig. 2a. The periodontal collagen fibers penetrate into the laminin positive basal lamina $(B L)$; the immunoreaction products for laminin are deposited on the surface of cross-sectioned collagen fibers (arrows). An arrowhead indicates an intracellular vesicle positive in reaction. $A T$ axon terminal, SS Schwann sheath. $\times 47,000$ 

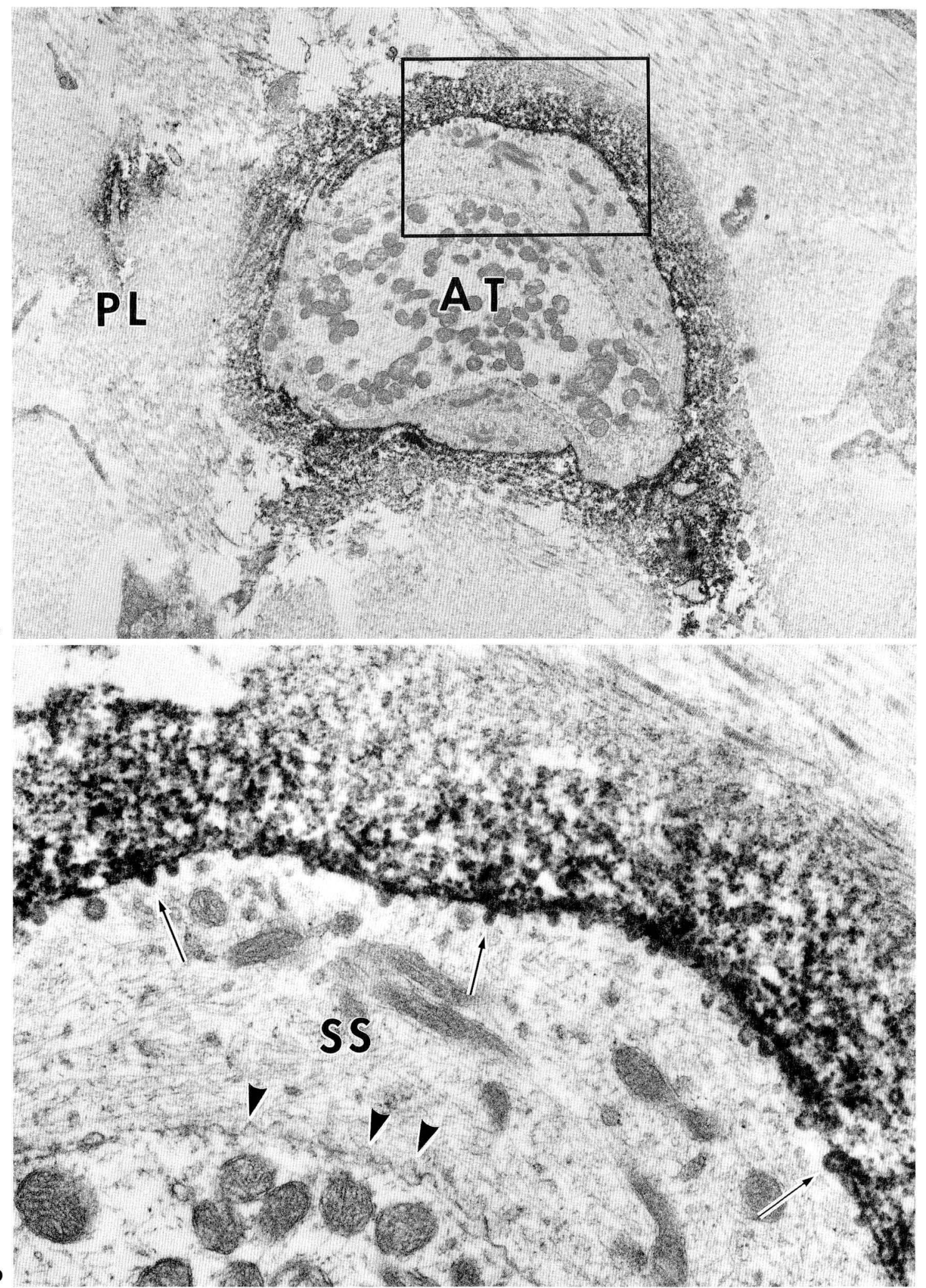

Fig. 3. Legend on the opposite page. 


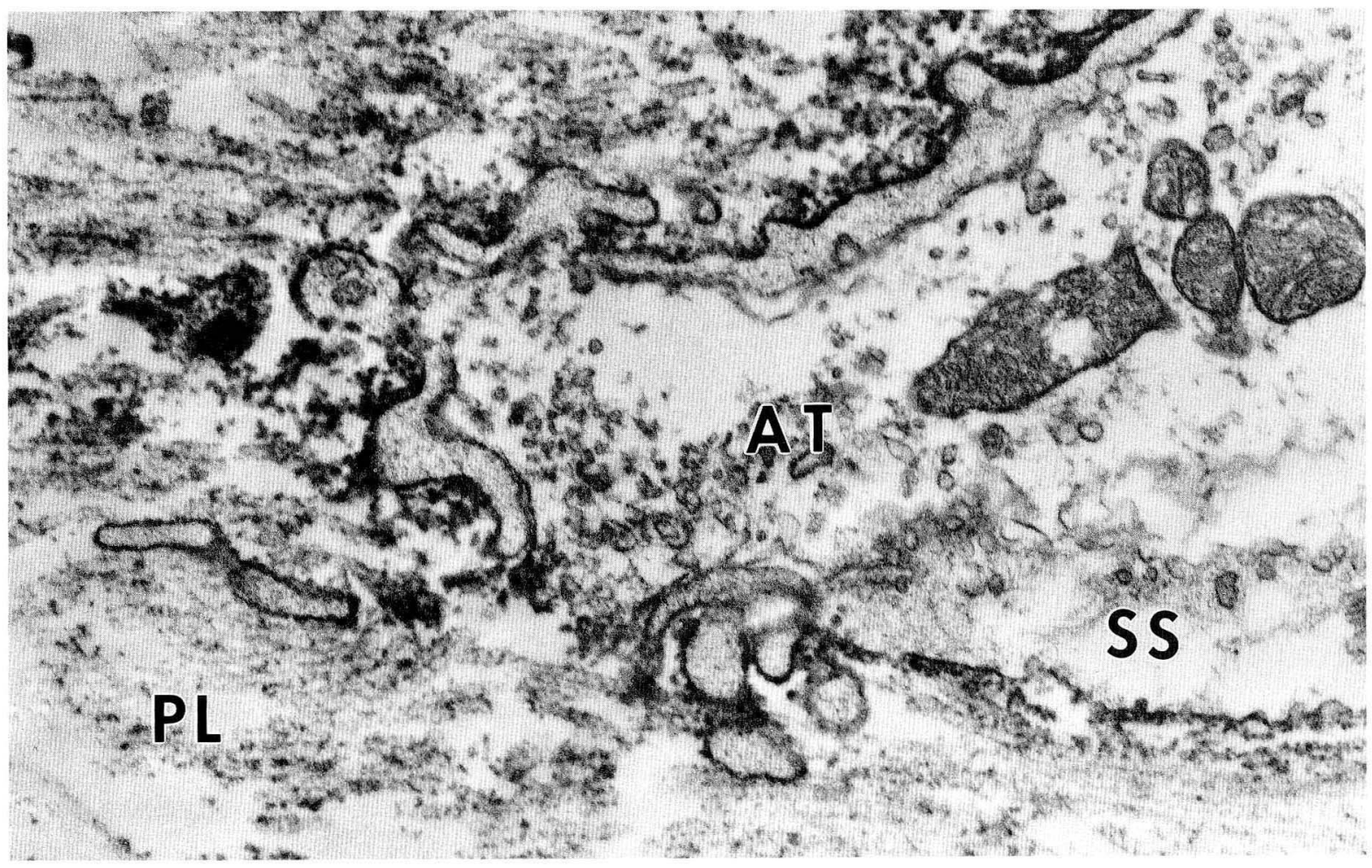

Fig. 4. Electron micrograph of the axon terminal ( $A T)$ of Ruffini ending. The outer surface of Schwann sheath $(S S)$ is intensely immunoreacted with the laminin antiserum. The periodontal collagen fibers was observed to penetrate the immunopositive masses, some of them being deposited with immunoreactive products. $P L$ periodontal ligament. $\times 22,500$

related to the functional and topographic peculiarity of the periodontal Ruffini endings. Our preliminary report showed that, in neonates of rats, the basal lamina in the periodontal Ruffini endings was single layered, and changed to multiple layered after the teeth commenced their occlusion (SATO et al., 1990). This finding easily leads us to the hypothesis that the multi-layered basal lamina is formed in order to protect the axon terminals against intense and consistent mechanical stimulation.

The mechanism of the lamellation in the basal lamina has been explained by a periodical occurrence of production, and possibly destruction, of the basal lamina, with a newly formed layer of basal lamina being repeatedly added inside the old basal lamina by the basal lamina-producing cell (PIERCE and NAKANE, 1967; VRACKO and BENDITT, 1972; VRACKO, 1974). This idea is supported by the finding obtained from the present study that the innermost layer in the multi-layered basal lamina was most intensely immunoreactive for antiserum against laminin.

The developed Golgi apparatus and rough endoplasmic reticulum in the terminal Schwann cells are reminiscent of an active synthesis of protein in the cells. It is likely that the terminal Schwann cells actively produce laminin and other proteoglycans, and are involved in the formation of the multi-layered basal lamina. Although the caveolae and intracellular vesicles of the terminal Schwann cells were immunoreactive for laminin, we failed to observe the immuno-

Fig. 3. Immunohistochemisty for laminin at the ultrastructural level. a. An axon terminal $(A T)$ of Ruffini ending is enveloped by thick Schwann sheath, and further by a multi-layered basal lamina decorated with electron dense materials. b. Higher magnification of the area enclosed within the box in Fig. 3a. Reaction products for laminin are deposited in the caveolae facing the periodontal ligament (arrows), while no immunoreaction is recognized in the caveolae facing another surface (arrowheads) of the Schwann sheath (SS). a: $\times 11,000$, b: $\times 37,500$ 


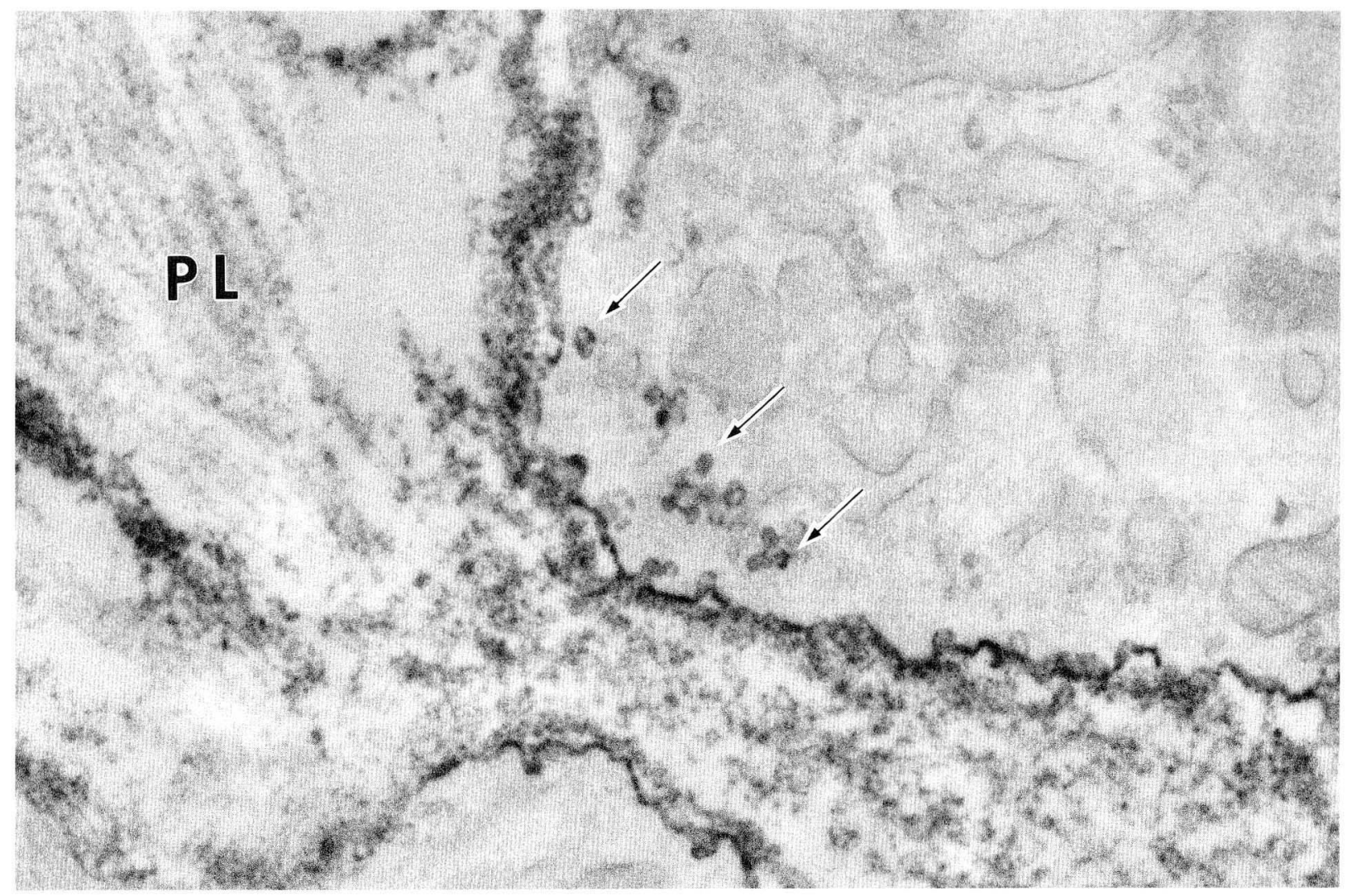

Fig. 5. Electron micrograph at the electron microscopic level of the cell body of a terminal Schwann cell. Electron dense materials are localized in the vesicles (arrows) near the cell membrane and caveolae. No immunoreaction is found in the endoplasmic reticulum and Golgi apparatus. PL periodontal ligament. $\times 40,000$

reactivity in the endoplasmic reticulum and Golgi apparatus. In contrast, some investigators have clearly demonstrated the localization of the laminin immunopositive materials in these cell organelles (LAURIE et al., 1982; WAKUI et al., 1990). Biochemical and autoradiographic study has suggested that a laminin precursor molecule without sugar components is present in the rough endoplasmic reticulum, completely changed into laminin in the Golgi apparatus, to be full-fledged in GERL and secretory granules, as is usually the case with glycoproteins (COPPER et al., 1981). The discrepancy with regard to the stainability of the endoplasmic reticulum and Golgi apparatus may be explained by the specificity of the antiserum used: our antiserum against laminin is believe to recognize only processed laminin molecules.

The caveolae and intracellular vesicles of the terminal Schwann cells showing the laminin immunoreactivity may presumably be involved in the transportion of laminin and other components of the basal lamina towards the axon terminals, although the detailed mechanism for the intracellular transportion and release of laminin is unknown. A nonspecific cholinesterase activity, which is a representative marker substance for mechanoreceptors, was also demonstrated in these terminal Schwann cells (MAEDA et al., 1990). This enzyme suggested to be synthesized by the cell bodies of terminal Schwann cells and conveyed towards the axon terminals. In contrast to the subcellular localization of the laminin immunoreactivity, the enzyme activity was localized more densely in the caveolae on the periaxonal spaces than in those facing the connective tissues (MAEDA et al., 1990). It seems that there are two kinds of vesicle-caveole systems in the terminal Schwann cells.

The periodontal Ruffini endings are a type of mechanoreceptor sensitive to the stretching of periodontal collagen fibers (CHAMBERS et al., 1972; Biemesderfer et al., 1978). The mechanism of this 
mechanoreception remains to be clarified in detail. Previous observations (BYERS, 1985; MAEDA et al., 1989) have suggested that the fingerlike projections extending from the axoplasm might be important for detecting or receiving the deformation of collagen fibers because these structures appeared to directly touch the periodontal collagen fibers. However, our careful observations using sections treated with tannic acid showed that the majority of the fingerlike projections did not contact the periodontal collagen fibers, a thick layer of the basal lamina instead interposing between them (KANNARI et al., 1991). The present immunohistochemical study confirmed the relationship between the fingerlike projections and periodontal collagen fibers; most of the fingerlike projections were embedded in the laminin positive basal lamina, with only a few of them being in direct contact with the periodontal collagen fibers. The multi-layered basal lamina produced by the terminal Schwann cells is conceived to serve as an adhesive device between the axon terminals and the collagen fibers. This adhesive structure seems important in transmitting the deformation of the collagen fibers to the axon terminals of the Ruffini endings.

Acknowledgments. The authors thank Mr. M. Hoshino for his photographic assistance.

\section{REFERENCES}

Andres, H. and M. Düring: Morphology of cutaneus receptors. In: (ed. by) A. IGGO: Handbook of sensory physiology, Vol. II. Somatosensory system. Springer, New York, 1973 (p. 3-28).

Beertsen, W., V. Everts and A. Van den Hooff: Fine structure and possible function of cells containing leptomeric organelles in the periodontal ligament of the rat incisor. Arch. Oral Biol. 19: 1099-1100 (1974).

Biemesderfer, D., B. L. Munger, J. Binck and R. DUBNER: The pilo-Ruffini complex: A non-sinus hair and associated slowly-adapting mechanoreceptor in primate skin. Brain Res. 142: 197-222 (1978).

Brockes, J. P., K. L. Fields and M. C. RAFF: Studies on cultured rat Schwann cells. I. Establishment of purified populations from cultures of peripheral nerve. Brain Res. 165: 105-118 (1979).

Byers, M. R.: Sensory innervation of periodontal ligament of rat molars consists of unencapsulated Ruffinilike mechanoreceptors and free nerve endings. J. Comp. Neurol. 231: 500-518 (1985).

Chambers, M. R., K. H. Andres, M. Düring and A. IGGO: Structure and function of the slowly adapting type II mechanoreceptor in hairy skin. Quart. J. Exp. Physiol. 57: 417-445 (1972).
Copper, A. R., M. Kurkinen, A. Taylor and B. L. M. Hogan: Studies on the biosynthesis of laminin by murine parietal endoderm cells. Eur. J. Biochem. 119: 189-197 (1981).

Cornbrooks, C. J., D. J. Carey, J. A. McDonald, R. TIMPL and R. P. Bunge: In vivo and in vitro observations on laminin production by Schwann cells. Proc. Nat. Acad. Sci. U.S.A. 80: 3850-3854 (1983).

Evercooren, A. B., H. K. Kleinman, H. E. J. SePPA, B. Rentier and M. Dubois-DALCQ: Fibronectin promotes rat Schwann cell growth and motility. J. Cell Biol. 93: 211-216 (1982).

IDE, C. and K. Tohyama: The localization of laminin and fibronectin on the Schwann cell basal lamina. Arch. Histol. Jap. 47: 519-532 (1984).

KANNARI, K.: Sensory receptors in the periodontal ligament of hamster incisors with special reference to the distribution, ultrastructure and three-dimensional reconstruction of Ruffini endings. Arch. Histol. Cytol. 53: 559-573 (1990).

Kannari, K., O. Sato, T. Maeda, T. Iwanaga and T. FUJITA: A possible mechanism of mechanoreception in Ruffini endings in the periodontal ligament of hamster incisors. J. Comp. Neurol. (1991, in press).

Laurie, G. W., C. P. Leblond and G. R. Martin: Localization of type IV collagen, laminin, heparan sulphate proteoglycan, and fibronectin to the basal lamina of basement-membranes. J. Cell Biol. 95: 340344 (1982).

Leblond, C. P. and S. Inoue: Structure, composition, and assembly of basement membrane. Amer. J. Anat. 185: 367-390 (1989).

Maeda, T., T. Iwanaga, T. Fujita, Y. Takahashi and S. KobaYASHI: Distribution of nerve fibers immunoreac tive to neurofilament protein in rat molars and periodontium. Cell Tiss. Res. 249: 13-23 (1987).

Maeda, T., O. Sato, S. Kobayashi, T. Iwanaga and T. FuJita: The ultrastructure of Ruffini endings in the periodontal ligament of rat incisors with special reference to the terminal Schwann cells (K-cells). Anat. Rec. 223: 95-103 (1989).

Maeda, T., K. Kannari, O. Sato, S. Kobayashi, T. IwANAGA and T. FuJITA: Cholinesterase activity in terminal Schwann cells associated with Ruffini endings in the periodontal ligament of rat incisors. Anat. Rec. 228: 339-344 (1990).

McLean, I. W. and P. K. Nakane: Periodate-lysineparaformaldehyde fixative: A new fixative for immunoelectron microscopy. J. Histochem. Cytochem. 22: 10771083 (1974)

Pierce, G. B., Jr. and P. K. Nakane: Antigens of epithelial basement membrane of mouse, rat and man. Lab. Invest. 17: 499-514 (1967).

Sato, O., T. MaEda, S. Kobayashi, T. Iwanaga, T. FuJita and Y. TAKAHASHI: Innervation of periodontal ligament and dental pulp in the rat incisor: An immunohistochemical investigation of neurofilament protein and glia-specific S-100 protein. Cell Tiss. Res. 251: 13-21 (1988). 
Sato, O., T. Maeda, S. Kobayashi and T. Imanaga: Innervation of the incisors and periodontal ligament in several rodents: An immunohistochemical study of neurofilament protein and glia-specific S-100 protein. Acta Anat. 134: 94-99 (1989).

Sato, O., K. Kannari, T. Maeda and S. Kobayashi: Postnatal development of Ruffini-like endings in the periodontal ligament of rat incisors (Abstract). Acta Anat. Nippon. 65: 42 (1990).

Sternberger, L. A.: Immunohistochemistry. 2nd ed. Prentice-Hall, Engerwood Cliffs, New York, 1979.

Vracko, R.: Basal lamina scaffold-Anatomy and significance for maintenance of orderly tissue structure. Amer. J. Pathol. 77: 314-346 (1974).

Vracko, R. and E. P. Benditt: Basal lamina: The scaffold for orderly cell replacement. Observations on regeneration of injured skeletal muscle fibers and capillaries. J. Cell Biol. 55: 406-412 (1972).
Wakui, S., M. Furusato, T. Nikaido, K. Yokota, J. SeKiguchi, K. Ohmori, Y. KanNo and S. Ushigome: Ultrastructural localization of fibronectin and laminin in human granulation tissue in relation to capillary development. Cell Struct. Funct. 15: 201-210 (1990).

Dr. Takeyasu MaEdA Department of Oral Anatomy Niigata University School of Dentistry Gakkocho 2, Niigata 951 Japan

前田健康 951 新潟市学校町 2 番町 .新潟大学歯学部 口腔解剖学第二教室 